\title{
Action Plan to Increase Physical Activity During the COVID-19 Pandemic
}

\author{
Amir-Hossein Memari, ${ }^{1}$ "Maryam Selk-Ghaffari, ${ }^{1}$ Afifeh Khosravi, ${ }^{1,2}$ Ramin Kordi ${ }^{1,3}$
}

\section{$\mathrm{T}$} He COVID-19 PANDEMIC, DEFINED AS A PUBliC Health Emergency of International Concern by the World Health Organisation (WHO) on 30 January 2020, has forced governments to take several public health mitigation measures including social and physical distancing, mask-wearing and hand hygiene. ${ }^{1}$ Such public health measures might become barriers to physical activity with major consequences on lifestyle during the COVID-19 pandemic., ${ }^{2,3}$ Physical activity is defined as any movement of the body, involving skeletal muscles and consuming energy. ${ }^{4}$ Based on the WHO recommendations, 150 minutes of moderate-intensity physical activity or 75 minutes of high-intensity physical activity is mandated for individuals to achieve health benefits. ${ }^{5}$ Physical activity and participation in sports have been shown to have protective effects against COVID-19. ${ }^{6-8}$ Additionally, physical activity is also a leading protective factor for chronic diseases that increase the severity and mortality rate of COVID-19. ${ }^{2}$

As of January 2021, COVID-19 has caused approximately 2 million deaths worldwide. ${ }^{9}$ However, noteworthy is the fact that physical inactivity leads to 3.6 million deaths worldwide annually. ${ }^{10}$ During the COVID-19 pandemic, the level of physical activity has been shown to have decreased. ${ }^{11,12}$ Based on the socio-ecological model, individual, interpersonal and environmental factors and governmental, community and organisational policies appear to have impact on physical activity. ${ }^{13}$

Challenges at the individual and interpersonal levels in engaging in physical activity consist of a variety of domains. Outlining the benefits of exercise, including positive effects on the immune system, might motivate more people to exercise regularly. ${ }^{14,15}$ Existing evidence indicates that moderate level of physical activity improves the immune system and reduces the risk of respiratory tract infection. ${ }^{16}$

Challenges at the environmental level consist of maintaining social distancing, sports clubs closure, cancelling and postponing matches. ${ }^{17,18}$ Public exercise facilities are locked down and limited opportunities for exercise are available. ${ }^{2}$ Home-based exercises, engaging in physical activity in a less crowded environment, considering the safe distance, and disinfecting probably contaminated surfaces (including sports equipment) could be a solution to this issue. ${ }^{19}$ Public space innovations might be considered as a motivation for engaging in physical activity. ${ }^{5,20}$

Challenges at the governmental, community and organisational levels consist of current governmental policies related to quarantine and isolation during the COVID-19 pandemic which prohibit individuals from any outdoor activities (United Kingdom, Italy, Spain, etc.). ${ }^{12,19,21,22}$ Current COVID-19 related policies might affect the level of physical activity. As an example, following the nation-wide lockdown, Italy showed a $48.7 \%$ decrease in the regional daily step count while in Sweden, which mainly issued gathering limitations and social distancing advice, a 6.9\% decrease was reported. ${ }^{12}$ As another example, physical inactivity increased in Spain following COVID-19 quarantine. ${ }^{22}$ Other critical considerations at the governmental level include the need for investments and addressing the inconsistencies in policies. ${ }^{5}$

\section{Physical Activity Action Plan During COVID-19 Pandemic}

According to a WHO report titled "Global action plan on physical activity (GAPPA) 2018-2030, more active people for a healthier world", GAPPA-systembased approaches are mandated to increase physical activity. ${ }^{5}$ Four main objectives should be targeted in the physical activity action plan including creating active society, active people, active environments and active systems. However, it is recommended that the four main objectives of GAPPA be modified according to the current COVID-19. The recommendations based on the aforementioned four objectives will be discussed below in tandem.

Creating active society is related to improving knowledge about the benefits of physical activity taking community standards, culture and beliefs into consideration. ${ }^{5}$ Providing information via social media about the benefits of physical activity on the prevention of COVID-19 is an applicable strategy. ${ }^{23}$ 
During the COVID-19 pandemic, the following policybased actions are recommended to increase physical activity with the objective of creating active people in the society through the intervention of physical activity stakeholders: (1) implementing applicable social campaigns to increase knowledge regarding the protective effects of physical activity against viral tract infections (COVID-19) and keeping active during the pandemic; (2) implementing communitybased initiatives in virtual public spaces that introduce and educate individuals on home-based exercise programmes suited to a variety of age groups with any level of ability (these programmes would ideally require a low budget, minimal equipment and be adaptable to the local culture); and (3) developing and conducting training courses for coaches and exercise experts to enhance their skills and utilisation of information in creating physical activity opportunities considering the social distancing and protection roles. ${ }^{19,24}$

Creating active environments, spaces and places is the second objective of GAPPA. ${ }^{5}$ Creating an active environment is related to providing appropriate, accessible and safe spaces for individuals of all ages with any level of ability to engage in physical activity. Although data available to make a recommendation in this domain are limited, existing evidence has showed that access to green and public spaces might increase the level of physical activity. ${ }^{20}$ During the COVID-19 pandemic, the following policy actions are recommended to increase physical activity with the objective of creating active environments: improving the infrastructure of walking and cycling networks considering the principles of social distancing by widening the sidewalks and dedicating specific cycling routes on roads through the intervention of governments and municipalities. ${ }^{25}$

Creating active people is the third objective of GAPPA..$^{5}$ This objective is related to providing and improving the availability of exercise and physical activity programmes and opportunities to support individuals of any age and ability to engage in physical activity. ${ }^{5}$ The following recommendations have been proposed for physical activity experts, physicians and stakeholders: (1) developing guidelines for home-based exercises through the intervention of physical activity experts.; (2) developing guidelines for professional athletes including cardiorespiratory considerations, necessary assessments and sanitary protocols before and during matches for safe return to the sport through the intervention of sport federations; (3) reinforcing the development and implementation of high-quality, virtual physical education and school- based physical activity programmes for children and adolescents through the intervention of physical activity stakeholders; and (4) Applying and improving virtual patient evaluation and management systems in patients recovering from COVID-19 to improve physical activity and conduct pulmonary rehabilitation via physicians..$^{19,26-28}$

Creating active systems, governance, and policies is the fourth objective of GAPPA. Creating active systems is related to develop and reinforce leadership, management, the co-operation of physical activity-related sectors, physical activity workforce skills, advocacy, and surveillance data systems to increase physical activity. ${ }^{2,5}$ Resource mobilisation and improving coordination via governments are mandated in the success of the physical activity action plan. ${ }^{5}$ Governmental intervention in improving data and surveillance systems to determine the physical activity level and barriers among patients and healthy individuals during the COVID-19 pandemic is required. ${ }^{2}$

The level of physical inactivity is increasing worldwide as a consequence of the COVID-19 pandemic and urgent actions are required to take place through collaborations with and/or interventions by governments, physical activity stakeholders and experts. ${ }^{5}$ Highlighting the impact of physical activity in reducing the severity and mortality of COVID-19 might be beneficial. ${ }^{6-8}$ Based on the socio-ecological model to reduce physical inactivity, the development of a set of 'physical activity during COVID-19 guidelines' via expert intervention, guidelines for safe return to sports for athletes via sports federations, school-based virtual physical activity interventions via stakeholders and exercise-based rehabilitation following COVID-19 via physicians are mandated. ${ }^{5}$ Governmental cooperation is required to implement such action plans during COVID-19 considering

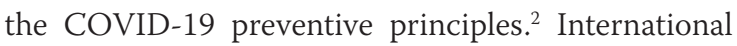
reinforcements (such as those provided by the WHO) might be beneficial in the success of the programme during the COVID-19 pandemic.

\section{AUTHORS' CONTRIBUTION}

A-HM and MS-G contributed to developing the concept and design of the work. AK conducted the literature assessment and information extraction. MS-G drafted the manuscript. A-HM and RK revised the original manuscript. All authors conducted the critical review of the final draft and approved final version of the manuscript. 


\section{References}

1. Sohrabi C, Alsafi Z, O'Neill N, Khan M, Kerwan A, Al-Jabir A, et al. World Health Organization declares global emergency: A review of the 2019 novel coronavirus (COVID-19). Int J Surg 2020; 76:71-6. https://doi.org/10.1016/j.ijsu.2020.02.034.

2. Sallis JF, Adlakha D, Oyeyemi A, Salvo D. An international physical activity and public health research agenda to inform COVID-19 policies and practices. J Sport Health Sci 2020; 9:328-34. https://doi.org/10.1016/j.jshs.2020.05.005.

3. Mattioli AV, Puviani MB, Nasi M, Farinetti A. COVID-19 pandemic: The effects of quarantine on cardiovascular risk. Eur J Clin Nutr 2020; 74:852-5. https://doi.org/10.1038/s41430020-0646-z.

4. Caspersen CJ, Powell KE, Christenson GM. Physical activity, exercise, and physical fitness: Definitions and distinctions for health-related research. Public Health Rep 1985; 100:126-31.

5. World Health Organization. Global action plan on physical activity 2018-2030: More active people for a healthier world. Geneva: World Health Organization; 2018. WHO/NMH/ PND/18.5. Pp. 1-104.

6. Hamer M, Kivimäki M, Gale CR, Batty GD. Lifestyle risk factors, inflammatory mechanisms, and COVID-19 hospitalization: A community-based cohort study of 387,109 adults in UK. Brain Behav Immun 2020; 87:184-7. https://doi.org/10.1016/j. bbi.2020.05.059.

7. Halabchi F, Mazaheri R, Sabeti K, Yunesian M, Alizadeh Z, Ahmadinejad Z, et al. Regular Sports Participation as a Potential Predictor of Better Clinical Outcome in Adult Patients With COVID-19: A Large Cross-Sectional Study. J Phys Act Health 2020; 18:8-12. https://doi.org/10.1123/jpah.2020-0392.

8. Mohamed A, Alawna M. Role of increasing the aerobic capacity on improving the function of immune and respiratory systems in patients with coronavirus (COVID-19): A review. Diabetes Metab Syndr 2020; 14:489-96. https://doi.org/10.1016/j. dsx.2020.04.038

9. Dong E, Du H, Gardner L. An interactive web-based dashboard to track COVID-19 in real time. Lancet Infect Dis 2020; 20:533-4. https://doi.org/10.1016/S1473-3099(20)30120-1.

10. Rosenbaum S, Ward PB. The simple physical activity questionnaire. Lancet Psychiatry 2016; 3:e1. https://doi.org/10.1016/ S2215-0366(15)00496-4.

11. Martinez EZ, Silva FM, Morigi TZ, Zucoloto ML, Silva TL, Joaquim AG, et al. Physical activity in periods of social distancing due to COVID-19: A cross-sectional survey. Cien Saude Colet 2020; 25:4157-68. https://doi.org/10.1590/1413812320202510.2.27242020.

12. Tison GH, Avram R, Kuhar P, Abreau S, Marcus GM, Pletcher MJ, et al. Worldwide effect of COVID-19 on physical activity: A descriptive study. Ann Intern Med 2020; 173:767-70. https:// doi.org/10.7326/M20-2665

13. Pratt M, Perez LG, Goenka S, Brownson RC, Bauman A, Sarmiento OL, et al. Can Population Levels of Physical Activity Be Increased? Global Evidence and Experience. Prog Cardiovasc Dis 2015; 57:356-67. https://doi.org/10.1016/j. pcad.2014.09.002.
14. Mabry R, Koohsari MJ, Bull F, Owen N. A systematic review of physical activity and sedentary behaviour research in the oil-producing countries of the Arabian Peninsula. BMC Public Health 2016; 16:1003. https://doi.org/10.1186/s12889-016-3642-4.

15. Midhet FM, Sharaf FK. Impact of health education on lifestyles in central Saudi Arabia. Saudi Med J 2011; 32:71-6.

16. Halabchi F, Ahmadinejad Z, Selk-Ghaffari M. COVID-19 epidemic: Exercise or not to exercise; that is the question. Asian J Sports Med 2020; 11:e102630. https://doi.org/10.5812/asjsm.102630.

17. Wong AY-Y, Ling SK-K, Louie LH-T, Law GY-K, So RC-H, Lee DC-W, et al. Impact of the COVID-19 pandemic on sports and exercise. Asia Pac J Sports Med Arthrosc Rehabil Technol 2020; 22:39-44. https://doi.org/10.1016/j.asmart.2020.07.006.

18. Hassanzadeh-Rad A, Halabchi F. Stadiums as Possible Hot Spots for COVID-19 Spread. Asian J Sports Med 2020; 11:e103178. https://doi.org/10.5812/asjsm.103178.

19. Dwyer MJ, Pasini M, De Dominicis S, Righi E. Physical activity: Benefits and challenges during the COVID-19 pandemic. Scand J Med Sci Sports 2020; 30:1291-4. https://doi.org/10.1111/sms.13710.

20. Mitra R, Moore SA, Gillespie M, Faulkner G, Vanderloo LM, Chulak-Bozzer $\mathrm{T}$, et al. Healthy movement behaviours in children and youth during the COVID-19 pandemic: Exploring the role of the neighbourhood environment. Health Place. 2020; 65:102418. https://doi.org/10.1016/j.healthplace.2020.102418.

21. Stephen S, Issac A, Jacob J, Vijay V, Radhakrishnan RV, Krishnan N. COVID-19: Weighing the endeavors of nations, with time to event analysis. Osong Public Health Res Perspect 2020; 11:149-57. https://doi.org/10.24171/j.phrp.2020.11.4.02

22. López-Bueno R, Calatayud J, Andersen LL, Balsalobre-Fernández C, Casaña J, Casajús JA, et al. Immediate impact of the COVID-19 confinement on physical activity levels in Spanish adults. Sustainability 2020; 12:5708. https://doi.org/10.3390/su12145708.

23. Hayes M. Social media and inspiring physical activity during COVID-19 and beyond. Manag Sport Leis 2020; 1-8. https:// doi.org/10.1080/23750472.2020.1794939.

24. Son JS, Nimrod G, West ST, Janke MC, Liechty T, Naar JJ. Promoting Older Adults' Physical Activity and Social WellBeing during COVID-19. Leis Sci 2020; 43:287-94. https://doi. org/10.1080/01490400.2020.1774015.

25. Lai KY, Webster C, Kumari S, Sarkar C. The nature of cities and the Covid-19 pandemic. Curr Opin Environ Sustain 2020; 46:27-31. https://doi.org/10.1016/j.cosust.2020.08.008.

26. Dominski FH, Brandt R. Do the benefits of exercise in indoor and outdoor environments during the COVID-19 pandemic outweigh the risks of infection? Sport Sci Health 2020; 16:583-8. https://doi.org/10.1007/s11332-020-00673-z.

27. Löllgen H, Bachl N, Papadopoulou T, Shafik A, Holloway G, Vonbank K, et al. Recommendations for return to sport during the SARS-CoV-2 pandemic. BMJ Open Sport Exerc Med 2020; 6:e000858. https://doi.org/10.1136/bmjsem-2020-000858.

28. Wang TJ, Chau B, Lui M, Lam G-T, Lin N, Humbert S. Physical medicine and rehabilitation and pulmonary rehabilitation for COVID-19. Am J Phys Med Rehabil 2020; 99:769-74. https:// doi.org/10.1097/PHM.0000000000001505. 